\title{
Plurals and Mereology
}

\section{Salvatore Florio ${ }^{1}$ (D) . David Nicolas ${ }^{2}$}

Received: 2 August 2019 / Accepted: 5 August 2020 / Published online: 26 October 2020

(C) The Author(s) 2020

\begin{abstract}
In linguistics, the dominant approach to the semantics of plurals appeals to mereology. However, this approach has received strong criticisms from philosophical logicians who subscribe to an alternative framework based on plural logic. In the first part of the article, we offer a precise characterization of the mereological approach and the semantic background in which the debate can be meaningfully reconstructed. In the second part, we deal with the criticisms and assess their logical, linguistic, and philosophical significance. We identify four main objections and show how each can be addressed. Finally, we compare the strengths and shortcomings of the mereological approach and plural logic. Our conclusion is that the former remains a viable and well-motivated framework for the analysis of plurals.
\end{abstract}

Keywords Mass nouns · Mereology $\cdot$ Model theory $\cdot$ Natural language semantics · Ontological commitment $\cdot$ Plural logic $\cdot$ Plurals $\cdot$ Russell's paradox $\cdot$ Truth theory

\section{Introduction}

A prominent tradition in linguistic semantics analyzes plurals by appealing to mereology (e.g. Link [40, 41], Landman [32, 34], Gillon [20], Moltmann [50], Krifka [30], Bale and Barner [2], Chierchia [12], Sutton and Filip [76], and Champollion [9]). ${ }^{1}$

\footnotetext{
${ }^{1}$ The historical roots of this tradition include Leonard and Goodman [38], Goodman and Quine [22], Massey [46], and Sharvy [74].

Salvatore Florio

s.florio@bham.ac.uk

David Nicolas

david.nicolas@ens.psl.eu

1 Department of Philosophy, University of Birmingham, Birmingham, United Kingdom

2 Institut Jean Nicod, Département d'études cognitives, ENS, EHESS, CNRS, PSL University, Paris, France
} 
The mereological approach to plural semantics has received strong criticisms from philosophical logicians who subscribe to an alternative framework based on plural logic (e.g. Boolos [5], Oliver and Smiley [57, 58], Rayo [65, 66], Yi [85], and McKay [47]). Some of the criticisms target a broader class of "singularist" semantic analyses that interpret plural expressions in terms of singular ones. The mereological approach is the most popular, and perhaps the most plausible, of these analyses.

These criticisms have been very influential in philosophy, providing grounds for the acceptance of plural logic in areas such as metaphysics and the philosophy of mathematics. What has been overlooked is that, once the mereological approach is properly understood, its proponents have the basic tools for responding. Our aim is to clarify what these responses can be and develop a systematical defense of this approach. ${ }^{2}$ This will help bridge the gap between the linguistic and philosophical literature.

In the first part of the article, we offer a precise reconstruction of the mereological approach and its semantic background, in order to enable a more meaningful debate. We focus on the best-known implementation of the approach-that of Godehard Link - but most of our discussion also applies to alternative implementations found in linguistics.

In the second part, we deal with the criticisms and assess their logical, linguistic, and philosophical significance. The literature contains a number of objections against the mereological approach, but it is not always clear whether (and, if so, how) they are related. We use the distinction between model theory and truth theory to disentangle and make more precise these objections. We contend that, upon analysis, there are four main objections, and we show how each can be addressed. Our defense is based on various considerations. For example, we emphasize that the relevant approach relies on a distinctive atomistic mereology. And we recommend that proponents of the mereological approach carefully distinguish certain object language notions from parallel notions in the metalanguage, following a broadly Tarskian strategy. We also note that counterparts of some of these objections can be raised against plural logica point that can be appreciated once the distinction between model theory and truth theory has been clearly drawn. After comparing the mereological approach with plural logic, we conclude that the former remains a viable and well-motivated framework for the analysis of plurals.

\section{The Mereological Approach to Plurals}

Mereology is the study of parthood relations. Its formal development provides a framework for comparing various theories of parts and wholes (see Simons [75] and Cotnoir and Varzi [13]). Each theory is based on a primitive mereological notion. For instance, we may start with a notion of improper parthood $(\leq)$ according to which

\footnotetext{
${ }^{2}$ For an earlier defense, see Nicolas [54].
} 
every object is part of itself. Using this primitive, we can define other notions, such as overlap, atomicity, and the sum of several entities (see Section 2.4).

The strength of a particular theory depends, of course, on the chosen axioms. These are often expressed in the standard language of first-order logic. A well-known set of axioms yields the so-called Classical Extensional Mereology (also known as General Extensional Mereology, see Varzi [80, sec. 4.4]). From the model-theoretic point of view, this theory describes complete Boolean algebras with the bottom element removed (this was essentially shown in Tarski [78]). ${ }^{3}$

The mereological analysis of plurals has two main components, each corresponding to a basic desideratum for a compositional semantics of natural language (Dowty et al. [15, pp. 44-46]). The first component is a model theory: it offers an account of the logical properties of sentences containing plurals, such as entailment, consistency, and equivalence (see Section 2.4 for examples). The second is a truth theory: it offers an account of the truth conditions of these sentences. Details about these components are given below. As we will see, a particular theory, namely a version of Classical Extensional Mereology, is central to both components. Logical properties are captured by translating natural language sentences containing plurals into a formal language governed by this theory. Moreover, after assuming in the metalanguage that the axioms of the theory are satisfied, the truth conditions are given by constraining the interpretations of natural language sentences so that plural terms denote mereological sums. Crucially, the metalanguage contains only singular expressions.

\subsection{Motivations}

An adequate semantics of natural language should explain the main properties of plural expressions. First, the semantics should characterize the various interpretations that sentences containing plurals can receive, including their collective and distributive readings. Here is an example using the verb phrase lifted the table:

(1) Annie, Bonnie, and Connie lifted the table.

This sentence can mean that Annie, Bonnie, and Connie lifted the table together. This is the collective reading. But the sentence can also mean that each of them lifted the table alone. This is the distributive reading. Some verb phrases only accept distributive interpretations: ${ }^{4}$

(2) Annie and Bonnie ran.

\footnotetext{
${ }^{3}$ More detailed discussions of Classical Extensional Mereology can be found in Pontow and Schubert [62], Hovda [26], and Cotnoir and Varzi [13, ch. 2].

${ }^{4}$ There may be another kind of reading, one that counts the sentence as true, for instance, when Annie and Bonnie lifted the table together, while Connie lifted it alone. This would be an intermediate reading between the collective reading and the distributive one. Accounting for readings of this kind raises a number of issues which, though interesting, will be set aside for the purposes of our discussion (see especially Gillon [20], Lasersohn [36], Schwarzschild [72], Landman [33], and Champollion [10]).
} 
This sentence can only mean that each of Annie and Bonnie ran. We call these verb phrases distributive.

Second, the semantics should account for the fact that plurals refer cumulatively (Bunt [6, pp. 254, 262], Link [40, p. 303]). Speaking loosely, adding guests to guests gives you more guests. This property is exhibited by the following, valid inference:

The students are guests

(3) The teachers are guests

The students and the teachers are guests

As will become clear, the algebraic structure of the underlying domain enables the mereological approach to account for the readings of plural sentences and for the fact that plurals refer cumulatively.

Third, it has long been observed that plurals and mass nouns have common properties. ${ }^{5}$ For example, mass nouns, just like plurals, can have collective and distributive readings.

(4) The furniture is heavy.

This sentence can mean that the furniture as a whole is heavy, but it can also mean that each piece of furniture is heavy. Moreover, mass nouns, like plurals, refer cumulatively (Quine [64, p. 83]). Again speaking loosely, adding water to water gives you more water. Furthermore, some constructions only combine with plurals and mass nouns, not with singular count nouns. For example, comparative phrases such as more cats and more wood are grammatical, whereas more cat is not. The same is true of the proportional quantifier most: most cats and most wood are grammatical, whereas most cat is not. ${ }^{6}$ In order not to miss significant generalizations, we should seek as much as possible to explain these common features in a unified way. By assigning similar algebraic structures to the denotations of plurals and mass nouns, the mereological approach can provide a high degree of unification.

Finally, an adequate semantics of plurals should account not only for the properties that plurals share with mass nouns, but also for the properties that they share with mass nouns and singular count nouns. Indeed, these three types of expressions combine in the same way with other types of grammatical expressions, including adjectives and verbs, several determiners (e.g. the, some, any, and no), and partitive constructions:

(5) The furniture/desk/chairs is/are heavy.

(6) Annie sold the/some furniture/desk/chairs.

(7) Connie cleaned part/some/half/most of the furniture/desk/chairs.

\footnotetext{
${ }^{5}$ Overviews can be found in Link [40], Gillon [20, 21], Moltmann [50], Nicolas [53, 56], Pelletier and Schubert [61], Chierchia [12], Carrara and Moltmann [8], Champollion [9], and Rothstein [70].

${ }^{6}$ Some proportional quantifiers have different forms for plurals and mass nouns, e.g. many/much, few/a little. Still, they distinguish between these expressions and singular count nouns, combining with the former but not with the latter.
} 
These data are easier to explain if we assume that the entities denoted by plurals, mass nouns, and singular count nouns belong to a single domain. The mereological approach makes precisely this assumption: the framework simply enriches the domain with special entities satisfying mereological axioms. Some versions of this approach assume separate mereologies for plurals and mass terms (e.g. Link [40, 41], Landman [32], and Champollion [9]), while other versions assume a single mereology for both (e.g. Gillon [20], Chierchia [11], Bale and Barner [2], Sutton and Filip [76], and Landman [34]). In any case, the new entities, just like the remaining entities in the domain, become available for the set-theoretic operations that yield other semantic values. So the framework is easily integrated with semantics as customarily developed in linguistics.

Let us summarize the desiderata we have discussed. In general, a semantics of plurals should account for the logical properties of sentences and for their truth conditions. In particular, it should capture the distinction between collective and distributive readings, the phenomenon of cumulative reference, the properties shared by plurals and mass nouns, as well as those shared by these two classes of expressions and singular count nouns. Moreover, it should be easy to integrate with the rest of semantics.

Our discussion will focus on a basic implementation of the mereological approach to plurals along the lines of Link [40], Landman [32, ch. 7] and Link [41, chs. 2, 6]. This implementation is based on individual mereology, an atomistic mereology that uses a primitive relation called individual parthood by Link. This relation must be distinguished from more familiar relations such as material parthood. For example, in the material sense, the roof of a house is part of the house, and neither of them is atomic. In contrast, individual mereology takes both the roof and the house to be atoms, ignoring their material parts and the fact that one is a material part of the other. According to the mereological approach, singular count nouns (such as house and roof) are true of atoms in the individual sense, while plurals are true of sums of atoms in this sense. Adopting individual mereology is consistent with adopting other mereologies, including atomless ones. Multiple mereologies can live side by side. ${ }^{7}$ The mereological approach to plurals simply holds that individual mereology is the appropriate one for the analysis of plurals. As we will see, an illicit assimilation of different mereologies (e.g. individual and material) is at the heart of one of the main objections to the mereological approach (Section 3.1). ${ }^{8}$

\footnotetext{
${ }^{7}$ For an example of how different mereologies may coexist, see Simons [75, chs. 1-3]. Simons adopts three parthood relations: one for ordinary objects and their parts, one for portions of matter and their parts, and one for classes and their parts. Link uses only two parthood relations, roughly corresponding to the last two used by Simons.

${ }^{8}$ It may also be useful to note that there is another notion of atomicity in the literature. A count noun is said to have atomic (or quantized) reference when the following holds with respect to a salient relation of parthood associated with the noun: if the noun is true of something that has proper parts, it is not true of any of those parts (see for instance Krifka [29], Gillon [20], Champollion [9], and Rothstein [70]). Thus, the count noun circle has atomic reference. It applies to a whole circle, but not to any of its proper parts. By itself, adopting individual parthood in the analysis of plurals leaves open the question whether count nouns have atomic reference. Nicolas [53, ch. 4] argues for a negative answer to this question.
} 
There are various reasons why we focus on a mereological approach based on individual mereology. To begin with, it has been very influential and some recent work retains its core features (e.g. Champollion [9]). Moreover, it has received a fully rigorous development, which makes easier a proper assessment of the philosophical criticisms. Furthermore, most of these criticisms have been stated with this framework in mind, though several of them can be reformulated so as to apply to alternative implementations of the mereological approach, including those mentioned above (Gillon [20], Chierchia [11], Bale and Barner [2], Sutton and Filip [76], and Landman [34]). Our responses to the criticisms can also be useful in the context of these alternative implementations.

We now present a basic formal framework for individual mereology. We hope that our exposition will be of interest even to readers who are acquainted with the literature. First, we offer a simplified and accessible overview of the central aspects of the framework. Second, we highlight some important methodological features. In particular, we explain how both a model theory and a truth theory can be associated with the framework. This will provide a suitable context in which the criticisms can be meaningfully reconstructed.

\subsection{Semantic Framework}

From the perspective of the semantic tradition stemming from the work of Richard Montague [52], semantics can be seen as involving three languages: a fragment of natural language, a formal language, and a metalanguage. Here, we are concerned with a simple fragment of English containing plurals. The formal language is used to specify the logical form of sentences of this fragment of natural language. On the mereological approach, the formal language is a first-order language together with some special vocabulary. The metalanguage is a fragment of English that includes set-theoretic and mereological vocabulary as well as the semantic notions of truth and satisfaction. We use it to formulate a model theory and a truth theory for the formal language. Crucially, the metalanguage is free of plurals on the mereological approach. ${ }^{9}$

One could try to dispense with the formal language and formulate a model theory and a truth theory directly for the fragment of natural language under study. However, this would require that we decide on a specific syntactic theory for this fragment. It is often more convenient to work with a formal language whose semantics can be developed, to some extent, independently of syntactic issues.

The basic idea behind the semantics is this. We first translate each sentence of the fragment of natural language into a formula of the formal language expressing

\footnotetext{
${ }^{9}$ We avoid using the term object language since it is ambiguous in this context. The term usually refers to the language under study. So it is equally appropriate for the fragment of natural language and for the formal language - both languages are objects of semantic analysis.
} 
its logical form. Then, in the metalanguage, we provide a model theory and a truth theory for the formal language.

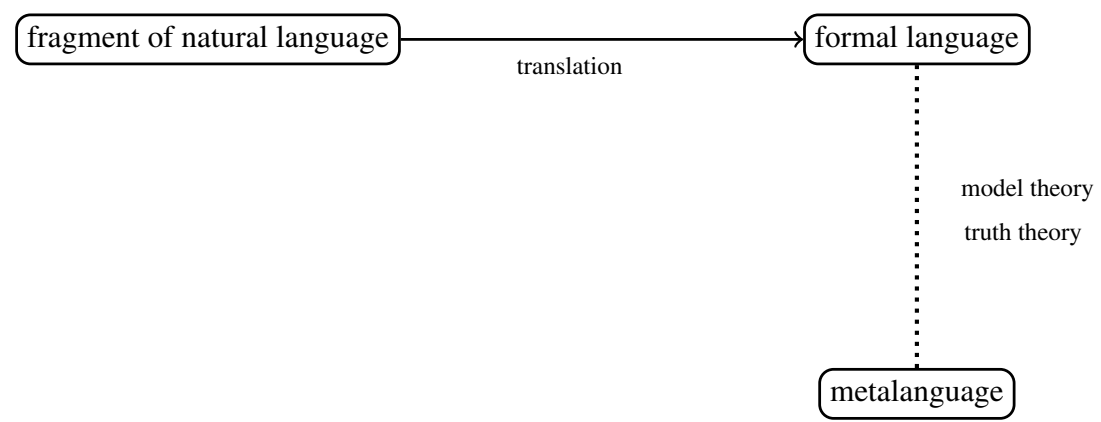

The model theory characterizes a relation of logical consequence for the formal language. This is meant to illuminate logical entailments among sentences of the fragment of natural language under study. To do so, the model theory must satisfy a condition that we call logical correctness. That is, the translation of a natural language argument should be validated by the model theory if and only if the argument itself is logically valid. ${ }^{10}$ As presented here, the model theory aims to account for logical entailments, such as those presented in our discussion of cumulative reference and distributivity (Section 2.1). By relying on meaning postulates (Carnap [7]), this framework is also able to capture other kinds of entailment involving expressions with related meanings.

The truth theory specifies the circumstances in which a sentence of the formal language is true. To serve as an indirect interpretation of natural language, the formal language with its truth theory must satisfy a condition that we call alethic correctness. That is, a sentence of natural language is true in certain circumstances if and only if its translation is true in the same circumstances.

Below we explain the distinctive feature of Link's mereological approach, namely the use of a relation of parthood in the formal language, constrained by the model theory and the truth theory to satisfy the axioms of an atomistic version of Classical Extensional Mereology.

\subsection{Translation}

Following Link [40, 41] and Landman [32], we focus on a formal language that augments the standard language of first-order logic with the following items:

(i) a relation of parthood $(\leq)$;

(ii) a special class of predicates, which we call atomic;

\footnotetext{
${ }^{10}$ The right-to-left direction of the requirement assumes that the formal language is sufficiently expressive. If not, some logically valid arguments may not be validated by the model theory. For example, propositional logic seems unsuitable to capture valid arguments that involve quantifiers in an essential way. So some valid arguments may not be validated by their propositional translation.
} 
(iii) four special operators: a pluralization operator *, a distributive operator ${ }^{\mathrm{D}}$, a summation operator $\sigma$, and a binary summation operator.$+{ }^{11}$

In this section, we give an intuitive idea of the semantics of these items. A precise characterization is provided in the following sections.

As mentioned, the translation maps sentences of natural language to formulas of the formal language. A common way of proceeding is to assign expressions of the lambda calculus to words of open classes. The translation of complex phrases can then be obtained compositionally by combining the appropriate lambda expressions. For example, the translation of Annie ran, i.e. $\operatorname{ran}(a)$, is derived as follows. First, we map Annie to $a$ and ran to $\lambda x \cdot \operatorname{ran}(x)$ :

$$
\begin{aligned}
\text { Annie } & \mapsto a \\
\text { ran } & \mapsto \lambda x \cdot \operatorname{ran}(x)
\end{aligned}
$$

Given the syntax of Annie ran, we obtain its translation by composition and conversion:

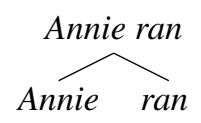

$$
\overbrace{a \quad \lambda x \cdot \operatorname{ran}(x)}^{\lambda x \cdot \operatorname{ran}(x)(a)[=\operatorname{ran}(a)]}
$$

This process depends on the choice of a particular syntactic analysis of the sentences of the fragment of natural language under study. To avoid complications, we make only minimal assumptions and settle on formalizations that can be recovered compositionally from standard theories of syntax.

Let us provide some details about the translations we will use, while keeping in mind that the meaning of the special vocabulary will be fixed by the model theory and by the truth theory. So it is only after these theories have been presented that the choice of translations will be vindicated.

First of all, atomic predicates translate singular count nouns and singular uses of distributive verbs:

$$
\begin{aligned}
\text { student } & \mapsto \lambda x \cdot \operatorname{student}(x) \\
r a n & \mapsto \lambda x \cdot \operatorname{ran}(x)
\end{aligned}
$$

This means that predicates like student and ran are true only of individual atoms. ${ }^{12}$

The pluralization operator * captures the semantic effect of the plural morpheme $-s$ :

$$
\text { students } \mapsto \lambda x .^{*} \text { student }(x)
$$

So, while student applies to any individual student, ${ }^{*}$ student applies to any mereological sum of students.

\footnotetext{
${ }^{11}$ While the symbol + is typically used in philosophy, the symbol $\oplus$ is often used in linguistics.

${ }^{12} \mathrm{On}$ this approach, count nouns are interpreted as atomic predicates. However, one might have to countenance exceptions to this rule. In particular, measure nouns such as liter and kilo seem to require a special semantic treatment—see Champollion [9, ch. 7], Rothstein [70, chs. 9-10], and references therein.
} 
The summation operator $\sigma$ captures the meaning of the definite article:

$$
\begin{aligned}
\text { the student } & \mapsto \sigma x . \operatorname{student}(x) \\
\text { the students } & \mapsto \sigma x .{ }^{*} \operatorname{student}(x)
\end{aligned}
$$

Essentially, the operator yields the mereological sum of the entities satisfying the formula bound by $\sigma$. Note that if there is only one student, $\sigma x \cdot \operatorname{student}(x)$ denotes this student.

The binary summation operator + corresponds to nominal conjunction:

$$
\text { Annie and Bonnie } \mapsto a+b
$$

In this example, it yields the mereological sum of the denotations of $a$ and $b$.

Finally, the distributive operator ${ }^{\mathrm{D}}$ is inserted when a verb phrase is understood distributively:

$$
\begin{array}{cl}
\text { Annie and Bonnie won } \mapsto \operatorname{won}(a+b) & \text { (collective reading) } \\
\text { Annie and Bonnie won } \mapsto^{\mathrm{D}} \text { won }(a+b) & \text { (distributive reading) }
\end{array}
$$

Intuitively, won $(a+b)$ means that the denotation of $a+b$ won as a team, whereas $\mathrm{D}_{\text {won }}(a+b)$ means that the denotations of $a$ and $b$ individually won. ${ }^{13}$

In the next section, we describe the model theory associated with the formal language used by the translation.

\subsection{Model Theory}

The model theory characterizes the relation of logical consequence for sentences of the formal language and hence, indirectly, for those of natural language. There are a number of reasons why a fully worked-out model theory is important. To begin with, such a theory is essential for determining whether the semantics captures the logical properties of plurals. Some of the phenomena described in Section 2.1, such as cumulative reference and distributivity, manifest themselves through logical relations. To capture these relations a model theory is required. Furthermore, some objections against the mereological approach involve logical considerations that can only be assessed once a model theory has been properly formulated (see especially the argument from incorrect existential consequence in Section 3.3).

In model theory, logical consequence is defined as truth preservation in every model of the language. Truth in a model is defined inductively using the appropriate features of the model. In this setting, a model is a structure $M=\langle\langle D, A, \sqcup\rangle, \llbracket \cdot \rrbracket\rangle$. The first component, $\langle D, A, \sqcup\rangle$, is a complete atomic Boolean algebra with the bottom element removed: $D$ is the domain; $A$, a subset of $D$, is the set of atoms; and $\sqcup$

\footnotetext{
${ }^{13}$ There is disagreement about exactly which linguistic phenomena require the use of such a distributive operator. For discussion, see e.g. Champollion [10, pp. 289-308].
} 
is the operation of join. ${ }^{14}$ The canonical partial order associated with this structure is defined as follows:

$$
x \sqsubseteq y={ }_{\operatorname{def}} x \sqcup y=y
$$

This relation provides the interpretation of individual parthood.

The second component of the structure, $\llbracket \cdot \rrbracket$, is an interpretation function assigning denotations to various expressions in the language. It satisfies the usual constraints. ${ }^{15}$ For example, the denotation of a term is an element of the domain, whereas the denotation of a predicate or an open formula is a set. In addition, the interpretation function satisfies constraints that ensure the intended semantics of parthood, atomic predicates, and the four special operators. An intuitive idea of this semantics was given in the previous section. We now offer a more precise characterization. ${ }^{16}$

The special relation $\leq$ is always interpreted as $\sqsubseteq$, the canonical partial order of the algebra. This ensures that $\leq$ satisfies the axioms of Classical Extensional Mereology in every model of the language. In other words, $\leq$ stands for a partial order satisfying the axiom of Strong Supplementation and the axiom scheme of Unrestricted Composition:

(Strong Supplementation) $\forall x \forall y(\neg x \leq y \rightarrow \exists z(z \leq x \wedge \neg z \circ y))$

(Unrestricted Composition) $\exists x \varphi(x) \rightarrow \exists z \forall w(w \circ z \leftrightarrow \exists x(\varphi(x) \wedge w \circ x))$

where the symbol $\circ$ stands for overlap, namely $x \circ y={ }_{\operatorname{def}} \exists z(z \leq x \wedge z \leq y) .{ }^{17}$

Given its interpretation as $\sqsubseteq$, the relation of parthood satisfies an additional mereological condition, namely Atomicity. Let us say that $x$ is an atom if it has no part other than itself:

$$
\operatorname{atom}(x)=_{\text {def }} \forall y(y \leq x \rightarrow y=x)
$$

Then Atomicity states that every object has an atom among its parts:

$$
\forall x \exists y(\operatorname{atom}(y) \wedge y \leq x)
$$

We require that atomic predicates denote either a set of atoms in the algebra or the empty set.

Let us now specify the constraints on the interpretation of the four operators introduced and intuitively explained in the previous section. The pluralization operator * applies to any atomic predicate $N$. If the denotation of $N$ is not empty, the denotation of* $N$ is the closure under join $(\sqcup)$ of the denotation of $N$. Otherwise the denotation of ${ }^{*} N$ is empty. The fact that plurals refer cumulatively follows from this interpretation of the operator*. We will see an example shortly.

\footnotetext{
${ }^{14}$ Given Stone's representation theorem, any complete atomic Boolean algebra is isomorphic to a powerset algebra. So we can think of a complete atomic Boolean algebra with the bottom element removed as a substructure of a powerset algebra. More precisely, we start with a set $U$ and obtain the algebraic structure $\langle\mathcal{P}(U)-\emptyset, A, \cup\rangle$. The domain of the algebra is $\mathcal{P}(U)-\emptyset$, the set of atoms $A$ is $\{\{x\}: x \in U\}$, and the join is the operation of set-theoretic union. Since the empty set has been removed, this structure is not closed under intersection and thus the operation of meet is only partial.

${ }^{15}$ See, e.g., Enderton [16, sec. 2.2].

${ }^{16}$ Since we focus on the interpretation of plurals, we may ignore complications arising from the analysis of linguistic phenomena such as tense and mood. As a result, there is no need to introduce time indices or possible worlds in the model theory.

${ }^{17}$ See Varzi [80, sec. 4] for more context and discussion.
} 
The distributive operator ${ }^{\mathrm{D}}$ applies to predicates of any kind and its interpretation is constrained as follows. Something is in the denotation of ${ }^{\mathrm{D}} P$ if and only if every atomic part of it is in the denotation of $P .{ }^{18}$ That is, every model satisfies this formula:

$$
\forall x\left({ }^{\mathrm{D}} P(x) \leftrightarrow \forall y(\operatorname{atom}(y) \wedge y \leq x \rightarrow P(y))\right)
$$

Finally, we specify the interpretation of the summation operators. Let $\varphi(x)$ be any formula where $x$ occurs free. Applying the operator $\sigma$ yields the term $\sigma x . \varphi(x)$ where $x$ is no longer free. If the denotation of $\varphi(x)$ is not empty and contains its own join, then the interpretation of $\sigma x . \varphi(x)$ is this join. Otherwise $\sigma x . \varphi(x)$ fails to denote. ${ }^{19}$ As for the binary operator + , it is interpreted as $\sqcup$. This means that $a+b$ denotes the join of the denotations of $a$ and $b$.

The model theory outlined in this section captures a variety of inferences. For example, it captures the logical relations characteristic of distributivity:

$$
\frac{\text { Annie and Bonnie run }}{\text { Annie runs and Bonnie runs }}
$$

$$
\mapsto \quad \frac{\mathrm{D}_{\operatorname{run}(a+b)}}{\operatorname{run}(a) \wedge \operatorname{run}(b)}
$$

The validity of this inference can be verified as follows. Suppose that the premise is true in a model, that is, the denotation of $a+b$ is in the denotation of ${ }^{\mathrm{D}}$ run. The interpretation of the distributivity operator ensures that the atoms denoted by $a$ and $b$ are both in the denotation of run. This reasoning makes the common assumption that a constant translating a singular proper name denotes an atom.

Similar algebraic reasoning explains why plural expressions like guests refer cumulatively:

(9) The students are guests

The teachers are guests

The students and the teachers are guests

$$
\mapsto \begin{gathered}
{ }^{*} \operatorname{guest}\left(\sigma x \cdot{ }^{*} \operatorname{student}(x)\right) \\
{ }^{*} \operatorname{guest}\left(\sigma x \cdot{ }^{*} \operatorname{teacher}(x)\right) \\
{ }^{*} \operatorname{guest}\left(\sigma x \cdot{ }^{*} \operatorname{student}(x)+\right. \\
\left.\sigma x .{ }^{*} \operatorname{teacher}(x)\right)
\end{gathered}
$$

Given the interpretation of the pluralization operator *, the denotation of *guest is closed under join. So if it contains the denotation of $\sigma x$. $^{*} \operatorname{student}(x)$ and that of $\sigma x .^{*} \operatorname{teacher}(x)$, it also contains the denotation of $\sigma x .^{*} \operatorname{student}(x)+\sigma x .{ }^{*} \operatorname{teacher}(x)$.

In this system, the key relation of being one of amounts to the relation of being an atomic part. So the sentence Annie is one of the students is translated as:

$$
\operatorname{atom}(a) \wedge a \leq \sigma x .{ }^{*} \operatorname{student}(x)
$$

\footnotetext{
${ }^{18}$ As mentioned, this operator is used for the distributive readings of verb phrases. To account for the intermediate readings mentioned in footnote 4 , one can introduce a more general version of the operator (for discussion, see Gillon [20, pp. 617-620], Schwarzschild [72, pp. 68-71], and Champollion [10, sec. 4.4]). Allowing for this generalization is one reason to distinguish the pluralization operator * and the distributive operator ${ }^{\mathrm{D}}$. The former applies to the translation of noun phrases, the latter to the translation of verb phrases.

${ }^{19}$ Note that, on this interpretation, the summation operation $\sigma$ does not correspond exactly to the join operation $\sqcup$, since it adds the extra condition that the join be in the denotation of $\varphi(x)$. This allows $\sigma$ to capture the meaning of the definite article as it combines with both singular and plural count nouns (see Landman [32, pp. 305-306]).
} 
It is easy to see how this translation captures intuitive inferences such as the following:

Annie is one of the students

$\frac{\operatorname{atom}(a) \wedge a \leq \sigma x \cdot{ }^{*} \operatorname{student}(x)}{\operatorname{student}(a)}$

Suppose that the premise is true in a model. The interpretation of $\sigma$ and the fact that student is an atomic predicate guarantee that the denotation of $a$ must be in the denotation *student. Since the denotation of $a$ is an atom and student is atomic, the algebraic closure effected by the pluralization operator * entails that the denotation of $a$ is also in the denotation of student.

We have provided a basic characterization of the model theory, and we have verified that it captures fundamental properties of plurals, such as distributivity and cumulative reference. We will now turn to the formulation of the truth theory.

\subsection{Truth Theory}

Proponents of the mereological approach to plurals such as Link [40], Landman [32], and Gillon [20] provide only a model theory. However, some philosophical objections do not make much sense in the context of a model theory and have bite only with respect to a truth theory. So we explain how one may develop a truth theory that complements the model theory presented above. We introduce a primitive relation of individual parthood in the metalanguage and assume that it satisfies the mereological axioms just mentioned. We then use individual parthood to interpret the relation $\leq$ of the formal language. This ensures that $\leq$ has the appropriate mereological behavior.

The basic principles of the truth theory mirror those of the model theory. ${ }^{20}$ For instance, one requires that an atomic predicate $N$ be satisfied only by mereological atoms, and that ${ }^{*} N$ apply to any sum of those atoms. Furthermore, suppose that $\varphi(x)$ is satisfied. Then $\sigma x . \varphi(x)$ denotes the sum of everything that satisfies $\varphi(x)$ provided that this sum also satisfies $\varphi(x)$. Otherwise $\sigma x . \varphi(x)$ fails to denote. Given the interpretation of,$+ a+b$ denotes the sum of the denotations of $a$ and $b$. As before, distributive readings are captured by a constraint on the interpretation of the operator $^{\mathrm{D}}$. For any predicate $P$, something satisfies ${ }^{\mathrm{D}} P$ if and only if every atomic part of it satisfies $P$.

To see how truth conditions are specified, consider the collective readings of the next two sentences (with people winning together as teams), followed by their translation:

(11) Annie and Bonnie won.

(12) The students won.

(13) $\operatorname{won}(a+b)$

\footnotetext{
${ }^{20}$ The literature contains two ways of framing the truth theory. One regards predicates as non-denoting expressions (see Larson and Segal [35, ch. 4]). The resulting truth theory is developed independently of the model theory. The other option, which is the most popular in linguistic semantics, assigns denotations to predicates. The truth theory can then be viewed as the result of applying the model theory to a model corresponding to the actual world. Our presentation is meant to be consistent with both options.
} 
(14) $\operatorname{won}\left(\sigma x \cdot *^{*} \operatorname{student}(x)\right)$

The truth conditions of (13) and (14) are given by (15) and (16), respectively:

(15) $\operatorname{won}(a+b)$ is true if and only if the denotation of $a+b$ satisfies the predicate won.

(16) $\operatorname{won}(\sigma x . * \operatorname{student}(x))$ is true if and only if the denotation of $\sigma x .^{*} \operatorname{student}(x)$ is not empty and satisfies the predicate won.

Given the principles stated above, the background mereology ensures that these truth conditions are equivalent to the following:

(17) won $(a+b)$ is true if and only if the sum of the denotations of $a$ and $b$ satisfies the predicate won.

(18) $\operatorname{won}\left(\sigma x \cdot{ }^{*} \operatorname{student}(x)\right)$ is true if and only if something satisfies the predicate *student and the sum of everything that satisfies this predicate satisfies the predicate won.

This concludes our exposition of the mereological approach. In the next section, we describe its main competitor within philosophical logic, namely plural logic. Being able to compare the two frameworks will be important when we turn to the objections to the mereological approach.

\subsection{Plural Logic}

In its most common form, plural logic represents plural predication in natural language using a type distinction that reflects the grammatical distinction between singular and plural. The formal language is obtained by expanding first-order logic with new types of variables, quantifiers binding them, and predicates. So there is a sharp distinction between singular and plural variables, quantifiers, and predicates.

Consider the following sentences in their collective readings (note that, in this paper, we adopt the philosophical use of the word thing, which does not presuppose inanimacy):

(11) Annie and Bonnie won.

(19) Some things won.

In plural logic, they can be translated as follows:

(20) $\operatorname{WON}(a \& b)$

(21) $\exists x x \operatorname{wON}(x x)$

where $a \& b$ is a plural term conjoining two singular terms, wON is a plural predicate, and $x x$ is a plural variable bound by a plural existential quantifier.

It is technically possible to implement the model theory for this formal language in set theory by assigning plural variables a domain with precisely the same algebraic structure as the one used for the mereological approach (see, e.g. McKay [47, ch. 5]). However, it is far more popular to formulate the model theory by adopting primitive plural resources in the metalanguage and using them to interpret the plural variables 
of the formal language (e.g. Rayo [66], McKay [47, ch. 6], Yi [86], and Oliver and Smiley [58, ch. 13]).

The main advantage of this kind of model theory is that it gets closer to the intended interpretation of the fragment of natural language under study than the set-theoretic model theory. A plural term is not taken to stand for a set. Rather, it stands for some things. Similarly, a domain of quantification can be described plurally as some things, those over which the quantifiers range. This appears to yield interpretations where the range of the quantifiers is not set-sized but unrestricted.

The price to be paid for this model theory is that the metalanguage has to go beyond plurals and include quantifiers of a new type (see Rayo and Uzquiano [67], Rayo [66], Yi [86], and Florio [17]), an observation that will be relevant in later sections (3.2 and 4). These new quantifiers can be of two kinds, depending on whether they bind variables in predicate position or in nominal position. Quantifiers of the former kind are called higher-order; quantifiers of the latter kind are often called superplural.

Let us briefly explain how this kind of model theory works. Suppose we adopt higher-order quantifiers. Then we can quantify into the predicate position of plural predicates:

\section{(22) $\exists X X(a \& b)$}

We may gloss this formula in terms of properties: there is a property jointly possessed by the denotations of $a$ and $b$. Using higher-order quantification, one can provide an interpretation of the collective reading of a plural predicate such as WON. The interpretation states that, in any model, there is a property $X$ for which the plural predicate WON stands.

Superplural quantifiers can play an analogous role. Intuitively, they enable quantification over "pluralities of pluralities":

\section{(23) $\exists x x x(a \& b$ are among $x x x \wedge c \& d$ are among $x x x)$}

This formula asserts that the denotation of $a \& b$ and the denotation of $c \& d$ are among some plurality of pluralities. The variable $x x x$ is superplural, bound by a superplural quantifier $\exists x x x$. Quantifiers of this kind can be used to provide an interpretation of the collective reading of plural predicates. The interpretation states that, in any model in which the predicate WON is satisfied, there is a superplurality $x x x$ for which it stands.

The ascent to resources of a new type is not needed for a truth theory. One can simply add to the metalanguage a new plural predicate for satisfaction. As a result, one may give the following truth conditions for the examples above:

WON $(a \& b)$ is true if and only if the denotations of $a$ and $b$ collectively satisfy the plural predicate WON.

$\exists x x \operatorname{WON}(x x)$ is true if and only if some things collectively satisfy the plural predicate WON. 
This completes our exposition of the core aspects of the mereological analysis of plurals and of plural logic. We are now ready to engage in an informed debate about the objections leveled against the analysis.

\section{Objections}

The literature contains a wealth of objections against the mereological approach, and it is not always clear whether (and, if so, how) they are related. In the rest of the article, we pursue two goals. The first is to offer a clear and useful picture of this landscape, which will help readers, both in philosophy and linguistics, orient themselves. The second is to assess the logical, linguistic, and philosophical import of the most significant objections. The methodological clarity provided by a precise formulation of the mereological approach is crucial in the pursuit of these goals.

We contend that the most significant objections can be divided into four kinds. The characteristic feature of objections of the first kind is that the relation of parthood used to analyze plurals is identified with some other mereological relation, e.g. material parthood. We call them flattening objections. The second kind of objection involves sentences featuring mereological notions. We refer to them as reflexivity objections. The third kind of objection concerns ontological commitment. Finally, there is an objection that questions the intelligibility of plural predication on the mereological account.

As presented above, the mereological approach has two main components: a model theory and a truth theory. By distinguishing between the two, a sharper formulation of the objections can be provided. This also puts the proponent of the mereological approach in a better position to respond. Once the distinction is drawn, the first two kinds of objection can be viewed as targeting both theories. (For ease of exposition, we present the version concerning the truth theory, which is easier to appreciate.) However, it also becomes clear that objections of the third and fourth kind have force only with respect to the truth theory. Furthermore, the distinction between model theory and truth theory reveals that counterparts of some of these objections can be raised against plural logic.

\subsection{Flattening}

Flattening objections exhibit the following pattern. Plurals are analyzed using a mereological relation other than individual parthood, and this is shown to have implausible consequences. Here is an example. Agustín Rayo writes:

Suppose that there are a few scattered piles of sand on the table. Then it is true of the piles of sand, but false of the grains of sand which make up the piles, that they are scattered. But, if we take mereological sums to be our surrogates, this fact cannot be captured [...], since the mereological sum of the piles is precisely the same object as the mereological sum of the grains of sand. (Rayo [65, pp. 444-445]) 
The objection begins with sentences (26) and (27), and their translations:

(26) The piles of sand are scattered.

(27) The grains of sand are not scattered.

(28) $\quad$ scattered $\left(\sigma x .^{*}\right.$ pile-of-sand $\left.(x)\right)$

(29) $\neg \operatorname{scattered}\left(\sigma x .^{*}\right.$ grain-of-sand $\left.(x)\right)$

In Section 2.2, we noted that a successful translation should satisfy what we called alethic correctness. Thus, in the envisioned scenario, the translation should satisfy these two conditions:

(i) (26) is true if and only if (28) is true;

(ii) (27) is true if and only if (29) is true.

According to the truth theory outlined in Section 2.5, the term $\sigma x .^{*}$ pile-of-sand $(x)$ denotes the sum of everything satisfying the predicate pile-of-sand $(x)$. Likewise, the term $\sigma x .^{*}$ grain-of-sand $(x)$ denotes the sum of everything satisfying the predicate grain-of-sand $(x)$. The argument makes the key assumption that these sums are identical. As a result, sentences (28) and (29) are taken to have opposite truth values: the first sentence says that this sum satisfies the predicate scattered $(x)$, whereas the second denies it. So it follows from conditions (i) and (ii) that (26) and (27) also have opposite truth values. But this contradicts what is stipulated in the example, namely that the piles of sand are scattered while the grains of sand are not.

In response to the objection, we should deny the key assumption that the sum denoted by $\sigma x .^{*}$ pile-of-sand $(x)$ is the same as the sum denoted by $\sigma x .^{*}$ grain-of-sand $(x)$. The assumption is plausible on a material reading of the notion of sum. On this reading, the assumption amounts to the claim that the stuff that makes up the piles of sand is the very same stuff that makes up the grains of sand. However, this understanding of the notion of sum is not the one operative in the semantics. The semantics is based on individual mereology, relative to which each pile of sand is an atom and each grain of sand is an atom. Two individual sums of atoms are identical just in case they have the same atoms. It follows that the individual sum of everything satisfying the predicate pile-of-sand $(x)$ is distinct from the individual sum of everything satisfying the predicate grain-of-sand $(x)$. Of course, the individual mereology operative in the semantics is consistent with the existence of other mereological relations. As we remarked earlier, an individual sum can have many material parts that do not correspond to its decomposition into individual atoms. $^{21}$

An alternative response may be available if the semantics of expressions like pile of sand differs from that of simple count nouns (see, for example, Schwarzschild [73], Pearson [60], Champollion [9], and Rothstein [70]). However, a response of this kind would not block other flattening objections, for example one put forward by Tom McKay [47, p. 42]. This objection involves regions of space.

\footnotetext{
${ }^{21}$ This version of the objection concerns the truth theory. One can formulate a version that targets the model theory by focusing on the consistency of sentences (26) and (27). Assuming that the model theory interprets the subjects in the same way, the translations of these sentences become inconsistent.
} 
There is a sense of parthood that applies to regions of space: a region of space can be part of another, and two regions can overlap, i.e. have a part in common. Now consider two regions, $a$ and $b$, that overlap. Let $a-r$ be the largest part of $a$ that does not overlap $r$. Likewise, let $b-r$ be the largest part of $b$ that does not overlap $r$. Then these two collective predications are true:

(30) Regions $a$ and $b$ overlap.

(31) Regions $a-r, b-r$, and $r$ do not overlap.

They are translated as follows:

(32) overlap $(a+b)$

(33) $\neg$ overlap $((a-r)+(b-r)+r)$

Relative to the mereology of spatial regions, the sum of the regions $a$ and $b$ is identical to the sum of the regions $a-r, b-r$, and $r$. So the term $a+b$ and the term $(a-r)+(b-r)+r$ denote the same region, namely this sum. Then, (32) and (33) have opposite truth values, unlike the sentences they translate.

It is easy to see that our response to the preceding example applies here too. The sense in which the sum of the regions $a$ and $b$ is identical to the sum of the regions $a-r, b-r$, and $r$ involves the mereology of spatial regions. But, again, this is not the notion of sum operative in the semantics. With respect to individual parthood, each region is a distinct atom. Therefore, the individual sum of $a-r, b-r$, and $r$ (three distinct atoms) cannot be identical to the individual sum of $a$ and $b$ (two other atoms).

Objections of this kind are an important reminder that a successful analysis of plurals must respect the distinction between individual parthood and other notions of parthood. Flattening otherwise distinct mereological relations has implausible consequences for the semantics.

In one of their early articles on plurals, Alex Oliver and Timothy Smiley also put forward a flattening objection:

wholes $[\ldots]$ can be decomposed into parts in many ways. This is why mereological sums or fusions are ineligible [to analyze English plurals]. For example, 'Whitehead and Russell' and 'the molecules of Whitehead and Russell' represent different decompositions of the same sum, but giving them that sum as their common reference forces the conclusion that the molecules of Whitehead and Russell were logicians. (Oliver and Smiley [57, p. 293])

They acknowledge the response offered above but contend that the appeal to individual parthood, which they call "the artificial mereology of 'lattice-theoretical' semantics", is still problematic. They claim that the mereological approach cannot provide a satisfactory semantics for the following sentence:

(34) The individual sums are more numerous than the individual atoms.

However, there is a crucial difference between this case and the previous examples: (34) explicitly involves mereological notions in the individual sense, while the previous examples do not. So (34) presupposes that the fragment of natural language under study contains the very mereological notions that are used in the semantics. 
This presupposition is the defining feature of the second kind of objection, to which we now turn.

\subsection{Reflexivity}

Assume for the moment that the fragment of natural language under study contains the very mereological notions that one wishes to use in the semantics. In our case, this is individual mereology. Then, as a number of authors have suggested, some sentences seem to receive an incorrect analysis. We call this phenomenon reflexivity to emphasize that these cases arise when the mereological vocabulary present in the metalanguage is reflected, and hence incorporated, into the fragment of natural language under study.

As indicated in Section 2.4, it is common to assume that a constant translating a singular proper name denotes an atom with respect to individual parthood. For the sake of argument, suppose that this assumption does not apply to the proper name $s$ and, hence, that $s$ denotes a non-atomic sum. Now consider this simple sentence:

(35) $s$ is a sum.

The sentence is true. According to the semantics, its translation $\operatorname{sum}(s)$ is true if and only if the denotation of $s$ satisfies the predicate sum. But, recall, the semantics requires that any singular count noun be translated as a predicate satisfied only by atoms. Because of this constraint, sum cannot be true of a non-atomic sum. So the semantics cannot account for the truth of (35), violating alethic correctness. (This objection can be found in Moltmann [50, pp. 18-19].)

Next, consider an example inspired by Barry Schein [71, pp. 33-37], which raises a problem even if we suppose that the translation of certain singular count nouns (such as non-atom) can be true of non-atomic sums:

(36) The atoms are the non-atoms.

This sentence is intuitively false. Its mereological translation is assumed to be (37):

$$
\sigma x .^{*} \operatorname{atom}(x)=\sigma x .^{*} \text { non-atom }(x)
$$

Here the predicate non-atom is taken to be satisfied by any non-atomic sum. Given the axioms of individual mereology, both terms flanking the identity sign in (37) denote the sum of everything satisfying the predicate atom. So (37) is true but (36) is not, which violates alethic correctness. ${ }^{22}$ The example given by Oliver and Smiley, i.e. sentence (34) above, can also be seen as problematic for similar reasons.

How can reflexivity objections be avoided? We think that a simple response is available to the defender of the mereological approach. This is to insist that the mereological notions used in the semantics be new, namely that they not be part of the language under study. Is this simple response too good to be true? We think not. Let us counter three objections that might be raised against this response.

\footnotetext{
${ }^{22}$ The objection can also be formulated so as to target the model theory. This is done by focusing on the intuitive inconsistency of (36).
} 
First, one might object that the new mereological resources are unintelligible and thus unsuitable for semantic theorizing. Can we make sense of them? Consider the truth and satisfaction predicates used in the metalanguage. We are working within a Tarskian framework in which these are assumed to be new with respect to the language under study (Tarski [77]). We make sense of these new predicates by laying out the axioms that govern them. And we make sense of the new mereological resources in exactly the same way. Proponents of plural logic face a similar issue. They, too, must introduce new resources. As noted in Section 2.6, their metalanguage involves new truth and satisfaction predicates as well as quantifiers of a new type. ${ }^{23}$

Second, one might object that the response we advocated makes plural talk of atoms and sums semantically unanalyzable. Suppose that these notions figure as count nouns in the singular metalanguage. Nothing, it appears, prevents us from pluralizing them and speaking of atoms and sums. One might expect the mereological approach to be able to give an analysis of these expressions. However, our response seems to make this impossible. For it requires the mereological notions used in the analysis of plurals to be new with respect to the language under study. So, if this language already contains these notions, the analysis offered above becomes unavailable. The obvious way out is to exploit the Tarskian approach embraced here, and to introduce new resources in the (meta-)metalanguage. An adequate analysis of plural talk of atoms and sums can be given by relying on new mereological notions, such as super-parthood, super-sum and super-atom. This step must then be iterated if one wishes to analyze plural talk involving these new notions. The iteration continues, and the effect is an ontological hierarchy of mereological levels, where the sums at one level are the atoms at the next level.

Third, one might object that the new expressive resources are not economical. The truth theory of the mereological approach introduces new truth and satisfaction predicates as well as new mereological notions. In contrast, the truth theory of plural logic relies only on new truth and satisfaction predicates. So why should one introduce more notions than strictly necessary? One reply in defense of our position is that the introduction of new mereological resources leads to an empirically adequate account of a variety of natural language phenomena (Section 2.1).

Moreover, it is important to be careful when assessing the expressive economy of competing frameworks: one should consider not only the truth theory, but also the model theory. Take the case of plural logic. Recall that the most popular model theory for this formal language goes beyond plurals and introduces quantifiers of a new type (Section 2.6). So, if one wants to analyze this new language, one needs to introduce yet another type of quantifier. The introduction of new resources continues, resulting in a type-theoretic hierarchy analogous to the ontological hierarchy postulated by proponents of the mereological approach (see, e.g., Rayo [66], Linnebo and Rayo [45], and Florio and Linnebo [18, ch. 11]). We come back to this

\footnotetext{
${ }^{23}$ This Tarskian framework, which relies on classical logic, is typically adopted by proponents of both the mereological approach and plural logic. Rejecting this framework opens up a number of possibilities that have been thoroughly studied in the literature on classical and non-classical theories of truth (see, e.g., Halbach [23] and Beall et al. [3]). It would be interesting to explore these possibilities in the context of the present debate. However, that would go much beyond the scope of this article.
} 
issue in Section 4, where we stress the benefits of the ontological hierarchy over the type-theoretic one.

For the moment, let us remark that the introduction of new levels of quantifiers raises difficult issues. To begin with, their intelligibility and legitimacy has been questioned. Famously, Quine rejected the use of higher-order quantifiers (Quine [63, pp. 66-68]). More recently, a number of authors have expressed doubts about superplurals (e.g. McKay [47, pp. 46-53] and Ben-Yami [4]). Moreover, a longstanding criticism is that adopting a hierarchy of such quantifiers gives rise to expressive limitations (see Linnebo [43] and Krämer [28] for a recent discussion). In this respect, the mereological approach is more economical, since its metalanguage contains only one type of quantifier.

Let us take stock of where we are so far. We have advocated a simple response to reflexivity objections, namely to use new mereological notions in the semantics, made intelligible through axioms. As we have seen, this response does not prevent one from giving a semantic analysis of talk of atoms and sums, if one wishes to do so. The new expressive resources are theoretically motivated, and they are not obviously less economical than those of plural logic. So we find no compelling way to substantiate the worry that the simple response is too good to be true.

Once it is recognized that adding new mereological vocabulary is legitimate, we have the resources to deal with another important argument against the mereological approach and, more generally, against singularist analyses of plurals. The argument is inspired by Russell's paradox (see Boolos [5, pp. 440-441], Lewis [39, p. 65], Schein [71, ch. 2], Higginbotham [24, pp. 16-17], Oliver and Smiley [57, pp. 303304], and Rayo [65, pp. 439-440]). It is easier to see the problem when the singularist uses sets to translate plurals. Considering this sentence:

(38) There are some sets such that any set is one of them if and only if it is not a member of itself.

Its translation is assumed to be the following:

$$
\exists x(\operatorname{set}(x) \wedge \exists y(y \in x) \wedge \forall y(y \in x \rightarrow \operatorname{set}(y)) \wedge \forall y(\operatorname{set}(y) \rightarrow(y \in x \leftrightarrow y \notin y)))
$$

The problem is that (39) is inconsistent: the sentence implies that there is a set that is a member of itself if and only if it is not. Yet, (38) seems to be true.

As is clear, the argument under discussion is just another reflexivity objection. The problematic sentence involves the very same notions that the semantics uses to analyze plurals, namely set and membership. Following the response advocated above, the singularist could introduce new set-theoretic notions (e.g. super-set and super-membership) to give an analysis of talk of sets and members in the plural. This strategy has been recently developed and defended in Meadows [49] (see also Williamson [82]). The move would enable the singularist to analyze (3.2) in this way:

$$
\begin{aligned}
\exists x(\operatorname{super}-\operatorname{set}(x) & \wedge \exists y(y \text { super-member-of } x) \\
& \wedge \forall y(y \text { super-member-of } x \rightarrow \operatorname{set}(y)) \\
& \wedge \forall y(\operatorname{set}(y) \rightarrow(y \text { super-member-of } x \leftrightarrow y \notin y)))
\end{aligned}
$$


This formula is not only consistent but also true if one adopts the appropriate axioms for super-sets.

The upshot is that, whether formulated in the context of set theory or mereology, arguments inspired by Russell's paradox are just instances of reflexivity objections. So they are blocked by the use of new semantic primitives in the analysis of plurals. The need for such primitives is a fact of life in semantics. ${ }^{24}$ Plural logic is not immune from it.

\subsection{Ontological Commitment}

So far, we have argued that neither flattening objections nor reflexivity objections pose a serious problem for the mereological approach. The third kind of objection we want to address has to do with ontological commitment (e.g. McKay [47, pp. 28-29]). Let us start with one of our earlier examples of plural predication:

(41) Annie and Bonnie won.

The translation of its collective reading is:

$$
\operatorname{won}(a+b)
$$

And its truth conditions are:

(43) won $(a+b)$ is true if and only if the sum of the denotations of $a$ and $b$ satisfies the predicate won.

If (42) is true, we can assert in the metalanguage that there exists a mereological sum. Together with alethic correctness, this implies (44):

(44) If Annie and Bonnie won is true, then there is a mereological sum.

Suppose that we have a clear-enough notion of ontological commitment for natural languages sentences, and suppose that (44) expresses an ontological commitment of (41). Then one can formulate an objection to the mereological approach relying on two premises. First, the truth of (41) makes in fact no commitment to the existence of sums (or any other kind of collection). Second, an adequate semantics should always respect the commitments of the sentences it analyzes. ${ }^{25}$

Concerning the first premise, it is important to note that intuitions about these commitments tend to vary (see, e.g., Boolos [5], Resnik [68], and Landman [31]; for

\footnotetext{
${ }^{24}$ As observed in footnote 23 , this conclusion depends on the assumption of a broadly Tarskian framework, which is typically made by both parties to the debate.

${ }^{25}$ One way to block the objection would be to claim that mereology is ontologically innocent and hence reject the presupposition that (44) expresses a genuine ontological commitment of (41). A number of authors, including David Armstrong, David Lewis, and more recently Achille Varzi and Rohan French, have defended the view that mereology is indeed ontologically innocent (see Armstrong [1, ch. 2, sec. 1.2], Lewis [39, ch. 3, sec. 6], Varzi [79], and French [19]). If one takes this view, a commitment to sums is no commitment at all. The relation of parthood used in the semantics of plurals is different from that discussed by these authors. However, similar arguments may be available for individual parthood (see Link [41, pp. 315-317]). Here we prefer not to take a stand on whether this kind of response is successful.
} 
an overview, see Linnebo [44, sec. 1.5]). Some have argued that plural quantification commits us to sets or set-like collections. In a similar vein, proponents of the mereological approach can simply insist that their analysis reveals the true commitments of plural sentences. So we agree with Øystein Linnebo that objections based on the notion of commitment should not be given significant weight (Linnebo [42]).

Moreover, an adequate semantics need not always respect the ontological commitments of the sentences it analyzes. This is because failing to respect these commitments may be offset by the advantages of the semantics. The classic example is Donald Davidson's analysis of predication (Davidson [14]). The analysis introduces ontological commitments to events, but it would be hard to maintain that these commitments can be recognized pre-theoretically. Yet, it is precisely the appeal to events that makes possible a simple and successful account of the semantics of adverbs. Something similar is true of the mereological approach: it provides a powerful way to account for important properties shared by plurals, mass nouns and singular count nouns (Section 2.1).

The problem of ontological commitment concerns the truth theory. It should not be confused with another kind of objection found in the literature (McKay [47, p. 23]; see also Oliver and Smiley [57, pp. 295-296], Yi [84, pp. 165-166], and Yi [85, pp. 468-469]). This kind of objection concerns logical consequence, and hence the model theory. Singular and plural expressions can make different logical contributions to inferences. The alleged problem is that the mereological approach misrepresents those contributions. Let us consider these sentences:

(45) Annie and Bonnie won.

(46) Something won.

Intuitively, a collective reading of (45) does not entail (46): Annie and Bonnie won together, so there need not be single entity that won. The objection is that the mereological approach will validate the incorrect inference from (45) to (46).

This objection is unfounded. The bare quantifier something in (46) is used in the singular. In Link's implementation of the mereological approach, singularity corresponds to atomicity. So the mereological translation of (45) and (46) is given by the following formulas:

(47) $\operatorname{won}(a+b)$

(48) $\exists x(\operatorname{atom}(x) \wedge \operatorname{won}(x))$

It is easy to verify that the step from (47) to (48) is invalid according to the semantics presented in Section 2.4. Take a model in which the denotation of $a+b$, a non-atomic sum, is the only entity in the denotation of won. In this model, (47) is true but (48) is false.

Moreover, if we assume that the count noun thing applies to all and only atoms in the domain, the semantics can be shown to capture the validity of the inference from (45) to (49):

(49) Some things won. 
This sentence is translated as (50):

$$
\exists x(\operatorname{atom}(x) \wedge \operatorname{won}(x))
$$

which is equivalent to

\section{$\exists x \operatorname{won}(x)$}

So we have no violation of the requirement of logical correctness. ${ }^{26}$ This shows that the mereological approach can account for the different logical contributions made by singular and plural expressions. It does so by means of the distinction between atoms and sums.

Exploiting this distinction, the mereological approach can also capture basic inferences involving numerical expressions. The collective reading of Annie and Bonnie won entails the "at least" reading of Two things won. The last sentence is true in a model if the intersection of the extensions of things and won contains a sum of at least two atoms. This suggests that there is no fundamental obstacle to a successful account of the meaning of numerical expressions within the mereological approach. The main idea is that counting is counting the atoms in a sum (Link [40, p. 319]). ${ }^{27}$ However, pursuing this idea would take us too far afield. ${ }^{28}$

\subsection{Intelligibility}

The fourth and last kind of objection concerns the intelligibility of plural predication. The charge is that the mereological approach relies, in the metalanguage, on predications that are not understood (see McKay [47, p. 24]). The problem arises in connection with the interpretation of collective predicates. For example, one might object that while we understand what it is for two people to win (together), we do not understand what it is for the mereological sum of two people to win.

Here are the truth conditions of the mereological translation of Annie and Bonnie won interpreted collectively:

(52) won $(a+b)$ is true if and only if the sum of the denotations of $a$ and $b$ satisfies the predicate won.

The objection is that these truth conditions are not intelligible: we do not understand what it is for the sum of the denotations of $a$ and $b$ to satisfy the predicate won. ${ }^{29}$

\footnotetext{
${ }^{26}$ The same reasoning would also explain the inference from Some water leaked, which uses a mass noun, to Something leaked. In Link's implementation of the mereological approach, anything a mass noun is true of (e.g. any portion of water) is also an atom within individual mereology (see Link [40, pp. 307-308, 313-314]). Material mereology lives inside individual mereology.

${ }^{27}$ What if we wanted to count individual sums? This would mean that the nominal expression individual sum is now part of the language under study. As explained in Section 3.2, we can make sense of this language by using a metalanguage with new mereological notions. Counting individual sums is then counting atoms in the new mereology.

${ }^{28}$ For recent surveys of linguistic issues surrounding counting, see Rothstein [70], Ionin and Matushansky [27], and Wellwood [81].

${ }^{29} \mathrm{~A}$ related objection is that we are unable to provide an informative characterization of the circumstances in which won is true of a sum. But this objection demands too much. For we are in the same situation with respect to all primitive predicates.
} 
There are two ways to respond. The first is based on the observation that we understand perfectly well what it is for a complex entity such as a group, a team, or a committee to have won. The sense in which the predicate won applies to a sum of people is just the sense in which it applies to these complex entities. So the truth conditions given in biconditionals like (52) are in fact intelligible.

A second response is also available if we adopt a widely used extension of Davidson's analysis of predication. ${ }^{30}$ According to this extension, all predicates, whether singular or plural, are treated as properties of events (where events encompass states). An important aspect of the analysis concerns the relations between events and their participants, known as thematic roles. For example, an event may have two participants, an agent and a patient. There is no consensus on the precise inventory of thematic roles. For our purposes, we may assume that there is a unique thematic role - that of being the agent-corresponding to the subject of any verb, including stative ones (see e.g. Champollion [9, pp. 33, 50-52]). Nothing crucial hinges on this simplifying assumption. The truth conditions of a singular predication $S(a)$ are as follows:

(53) $S(a)$ is true if and only if there is an event $e$ such that $e$ satisfies the predicate $S$ and the denotation of $a$ is the agent of $e$.

How can this analysis be applied in the case of plural predication? In the mereological approach, a plural subject denotes a mereological sum of atoms. One may regard this sum as the agent of the underlying event. Alternatively, one may regard each of its atoms as a co-agent of the event, namely as a participant sharing the agent role. In that case, the mereological sum denoted by the subject functions as "repository" for the joint participants. The two alternatives are exemplified by the following truth conditions: ${ }^{31}$

(54) won $(a+b)$ is true if and only if there is an event $e$ such that $e$ satisfies the predicate won and the sum of the denotations of $a$ and $b$ is the agent of $e$.

won $(a+b)$ is true if and only if there is an event $e$ such that $e$ satisfies the predicate won and, for every $x, x$ is a co-agent of $e$ just in case $x$ is an atom and $x$ is part of the sum of the denotations of $a$ and $b$.

No matter which option is chosen, singular and plural predication are treated on a par. Predication involves the application of a predicate to an event and the specification of the agent or co-agents of the event. So one cannot doubt the intelligibility of the treatment of plural predication without doubting that of singular predication, and hence the intelligibility of the framework as a whole. But event semantics is a well-established and successful framework, routinely used by many linguists and philosophers. We see no reason to doubt the coherence of their research and the intelligibility of the event-based analysis of predication.

Oliver and Smiley have argued that, in the presence of plurals, the second implementation of the Davidsonian analysis leads to paradox (Oliver and Smiley Oliver

\footnotetext{
${ }^{30}$ See, for instance, Parsons [59], Higginbotham [25], Landman [33], and Champollion [9].

${ }^{31}$ For a comparison, see Landman [33, ch. 3, sec. 3.2, 3.3].
} 
and Smiley [57, pp. 301-305], [58, pp. 40-41,44-49]). The argument proceeds as follows. Presumably, some events are not co-agents of themselves. For example, the writing of Principia Mathematica has only two co-agents: Whitehead and Russell. It is then assumed that there is a sense in which the following sentence is true:

(56) The events that are not co-agent of themselves are many.

The intended meaning is captured by this translation:

$$
\exists e(\operatorname{being}-\operatorname{many}(e) \wedge \forall x(\operatorname{co-agent}(x, e) \leftrightarrow(\operatorname{event}(x) \wedge \neg \operatorname{co-agent}(x, x))))
$$

However, on the assumption that the predicate event is true of $e,(57)$ is inconsistent: the formula implies that $e$ is a co-agent of itself if and only if it is not. Still, (56) is assumed to be true. It is worth noting that the problem at hand is not specific to the mereological approach. One is led to (57) whether one appeals to mereological sums, sets, properties, or things as "repositories" of co-agents. So this is first and foremost a problem for the implementation of event-based semantics that uses co-agents.

How should one deal with this problem? It can be seen as a reflexivity objection and, in particular, as a variant of the argument inspired by Russell's paradox discussed in Section 3.2. There, we defended a simple response to reflexivity objections that requires the mereological notions used in the semantics to be new with respect to the fragment of natural language being analyzed. Here we have an analogous situation: the event-theoretic notions used to analyze predication appear in our fragment of natural language. The paradoxical sentence, as before, exploits this fact. So a simple way to sidestep the problem is to require that the event-theoretic notions used in the semantics be new. This means that (57) would receive a translation along the lines of (58):

$$
\exists e\left(\operatorname{being-many}(e) \wedge \forall x\left(\operatorname{co-agent}{ }^{\prime}(x, e) \leftrightarrow(\operatorname{event}(x) \wedge \neg \operatorname{co-agent}(x, x))\right)\right)
$$

where co-agent ${ }^{\prime}$ is a new event-theoretic notion of co-agent. Crucially, this move yields a consistent translation. In Section 3.2, we addressed the concern that this style of response might be too good to be true. Our earlier defense extends to the present case- the relevant considerations carry over. Specifically, three key points hold: the new metalanguage can be given a semantics; the new notions are made intelligible by means of mereological and event-theoretic axioms; and the overall framework is justified by its theoretical virtues. Note that the simple response we advocated is implicit in semantics that treat objects and events as having different types (see, e.g., Landman [33, pp. 179-181] and Champollion [9, pp. 25-27]).

In connection with our discussion of the intelligibility objection, we would like to emphasize that plural logic is not immune from worries about intelligibility. In Sections 2.6 and 3.2, we remarked that a model theory for plural logic requires that one go beyond plurals and introduce quantifiers of a new type. The semantic values of plural predicates are then specified by means of variables bound by such quantifiers. Are these new resources intelligible? When confronting this question, some authors have suggested that they must be learned by "direct method" (e.g. Williamson [83] and Rayo [66]). Timothy Williamson writes: 
We must learn to use higher-order languages as our home language. Having done so, we can do the semantics and metalogic of a higher-order formal language in a higher-order formal meta-language of even greater expressive power. [...] What we are willing to take as our home language is partly a matter of what we feel comfortable with; unfortunately, it can be hard to argue someone into feeling comfortable. (Williamson [83, p. 459])

The proponent of the mereological approach and the proponent of plural logic are thus in a similar position. They make different choices of primitives, governed by different sets of axioms. However, as witnessed by the debate between them, both find it hard to argue the other into feeling comfortable with their choice. How can we make progress? We have argued that the main objections found in the literature do not undermine the mereological approach. In the next and final section, we discuss arguments that militate in its favor.

\section{Choosing between Frameworks}

An important virtue of the mereological approach is that plurals and mass terms can be analyzed with a high degree of unification. Our defense has focused on the version of the approach developed by Link, which postulates different mereologies for these two types of term (Link [40], Landman [32, ch. 7], Link [41, chs. 2, 6], Champollion [9, pp. 25-26]). In this version of the approach, the quantifier all receives a single meaning, no matter whether it combines with plurals or mass terms. It is interpreted as quantification over the entire domain, which includes atoms as well as sums. For instance, the sentences All rings were stolen and All gold was stolen are true if everything in the denotations of rings and gold, respectively, satisfies the predicate stolen. Similarly, the proportional quantifier most and the comparative expression more can both be interpreted as having a single meaning.

Link's version of the mereological approach provides less unified treatments of cumulative reference and the definite article. For it relies on different operations of sum formation: the one for plurals is relative to individual mereology, while the one for mass nouns is relative to material mereology (Link [40, p. 315]). However, there are other versions of the mereological approach which postulate a single mereology for both plurals and mass terms (e.g. Gillon [20], Chierchia [11, 12], Bale and Barner [2], Sutton and Filip [76], and Landman [34]). They can account for cumulative reference and interpret the definite article using a single operation of sum formation. Thus these versions of the approach seem to achieve an even higher degree of unification than those based on two mereologies.

Another important virtue of the mereological approach is that the use of mereology is easily integrated with the rest of semantics. The metatheory in which semantics is typically carried out is based on first-order set theory. We start with domains of primitive entities, such as objects and truth values, serving as semantic values. These domains are sets. On the mereological approach, we simply expand the domain of objects to include special entities satisfying mereological axioms. Then we build more complex kinds of semantic value using set-theoretic operations. For example, 
the semantic values of unary predicates translating common nouns and intransitive verbs are functions from objects to truth values. As a result, linguists who follow this approach can keep doing business as usual.

Does plural logic possess comparable virtues? Plural logic, per se, does not cover mass terms, and it is an open question whether it allows an empirically adequate analysis of plurals and mass terms with a high degree of unification. In this context, there are two broad options to account for mass terms. The first treats mass terms as singular terms. Then, the semantics interprets quantifiers and comparative expressions ambiguously. For instance, it assigns one meaning to all when it combines with a plural term and a different one when it combines with a mass term. Since these two meanings are distinct, the treatment of plurals and mass terms is less unified.

The second option accounts for mass terms using plural logic (Nicolas [55]). ${ }^{32} \mathrm{It}$ treats them as plural terms, forcing one to reject the standard view that mass terms are semantically singular. This option would afford a high degree of unification, since it postulates perfect semantic parity between plurals and mass terms.

While there has been some additional effort to extend the application of the framework of plural logic (e.g. Yi [87] and Moltmann [51]), a wide variety of natural language phenomena still fall outside its scope. So one cannot claim that the semantic benefits of plural logic compare with those of the mereological approach. In this sense, the applicability of plural logic to natural language semantics is still promissory.

Moreover, the question remains whether plural logic can be integrated with the rest of semantics. A clear obstacle is the following. The semantic value of a plural term is neither a primitive entity nor a set of primitive entities. Rather, it belongs to a new primitive type: things. But an instance of this type cannot be an element of a set. (While each of Russell and Whitehead can be an element of a set, Russell and Whitehead as many cannot.) An important consequence is that one can no longer build complex semantic values using just set-theoretic operations. In particular, expressions such as predicates, adjectives, and adverbs must be given a new kind of interpretation. This means that plural logic cannot be easily integrated with semantics as currently developed by linguists.

This seems to leave proponents of plural logic with two options. They can develop the type-theoretic hierarchy so that it mirrors the set-theoretic one (see, e.g., Linnebo and Rayo [45]). ${ }^{33}$ But then the two hierarchies become essentially notational variants of each other, and it is not clear whether there is any difference between the two

\footnotetext{
${ }^{32}$ Related approaches have been sketched by Laycock [37] and McKay [48]. However, these approaches postulate a primitive form of reference associated with mass terms. Therefore, they offer a less unified account of plurals and mass terms.

${ }^{33}$ Our contrast between semantic frameworks that rely on set theory and those that rely on type theory might appear odd to some readers. After all, talk of types is ubiquitous in ordinary natural language semantics, which we claim belongs to the first camp. However, this talk is usually cashed out in set-theoretic terms: each type is just a set of entities. For example, the type of unary predicates is just the set of functions from objects to truth values.
} 
perspectives and the associated semantics. ${ }^{34}$ Alternatively, if they think that the two hierarchies do not mirror each other, they have to show that a satisfactory semantics of natural language can in fact be developed within the type-theoretic hierarchy. Moreover, they have to establish that the benefits of this new semantics outweigh (or at least match) those of its set-theoretic rival. Unless this is done, we see no reason to abandon the safe and comfortable home of set theory.

Acknowledgements For helpful comments and discussion, we would like to thank Francesca Boccuni, Andrea Borghini, Colin Caret, Dick Carter, Hana Filip, Brendan Gillon, Simon Hewitt, Thomas Hofweber, David Liebesman, Øystein Linnebo, Manuel Rebuschi, Gonzalo Rodriguez-Pereyra, Ian Rumfitt, Barry Schein, Stewart Shapiro, Eric Snyder, Peter Sutton, Timothy Williamson, Sandro Zucchi, and two anonymous referees. We would also like to thank the audiences at the following venues: ESSLLI 2017, Heinrich-Heine-Universität Düsseldorf, Institute of Philosophy in London, Tokyo Forum for Analytic Philosophy, Università di Milano, Université de Lorraine, University of Oxford, and Yonsei University. Salvatore Florio's research was partly funded by a Leverhulme Research Fellowship. David Nicolas acknowledges the support provided by the grant ANR-17-EURE-0017 and by a Distinguished Visiting Fellowship from the Institute of Advanced Studies at the University of Birmingham.

Open Access This article is licensed under a Creative Commons Attribution 4.0 International License, which permits use, sharing, adaptation, distribution and reproduction in any medium or format, as long as you give appropriate credit to the original author(s) and the source, provide a link to the Creative Commons licence, and indicate if changes were made. The images or other third party material in this article are included in the article's Creative Commons licence, unless indicated otherwise in a credit line to the material. If material is not included in the article's Creative Commons licence and your intended use is not permitted by statutory regulation or exceeds the permitted use, you will need to obtain permission directly from the copyright holder. To view a copy of this licence, visit http://creativecommonshorg/licenses/by/4.0/.

\section{References}

1. Armstrong, D.M. (1997). A world of states of affairs. Cambridge: Cambridge University Press.

2. Bale, A.C., \& Barner, D. (2009). The interpretation of functional heads: Using comparatives to explore the mass/count distinction. Journal of Semantics, 26(3), 217-252.

3. Beall, J., Glanzberg, M., Ripley, D. (2018). Formal theories of truth. Oxford: Oxford University Press.

4. Ben-Yami, H. (2013). Higher-level plurals versus articulated reference, and an elaboration of salva veritate. dialectica, 67(1), 81-102.

5. Boolos, G. (1984). To be is to be a value of a variable (or to be some values of some variables). Journal of Philosophy, 81(8), 430-449.

6. Bunt, H.C. (1979). Ensembles and the formal semantic properties of mass terms. In Pelletier, F.J. (Ed.) Mass terms: some philosophical problems (pp. 249-277). Dordrecht: D. Reidel Publishing Company.

7. Carnap, R. (1952). Meaning postulates. Philosophical Studies, 3(2), 65-73.

8. Carrara, M., \& Moltmann, F. (2016). Introduction. In Carrara, M., Arapinis, A., Moltmann, F. (Eds.) Unity and plurality: Logic, philosophy, and linguistics (pp. vii-xv). Oxford: Oxford University Press.

9. Champollion, L. (2017). Parts of a whole: Distributivity as a bridge between aspect and measurement. Oxford: Oxford University Press.

10. Champollion, L. (2019). Distributivity in formal semantics. Annual Review of Linguistics, 5(1), 289308 .

\footnotetext{
${ }^{34} \mathrm{~A}$ particular example of this issue arises in connection with the one-sorted formulation of plural logic (see, e.g., Rieppel [69, pp. 512-513]). This theory employs only one type of variables, namely plural variables, and characterizes objects as one-membered pluralities (formulations of this theory can be found in Rayo [65, pp. 451-453] and McKay [47, pp. 120-124]). The result is in effect a notational variant of the atomistic version of Classical Extensional Mereology.
} 
11. Chierchia, G. (1998). Plurality of mass nouns and the notion of semantic parameter. In Rothstein, S. (Ed.) Events and grammar (pp. 53-104). Dordrecht: Kluwer Academic Press.

12. Chierchia, G. (2010). Mass nouns, vagueness and semantic variation. Synthese, 174(1), 99-149.

13. Cotnoir, A., \& Varzi, A. (Forthcoming). Mereology. Oxford: Oxford University Press.

14. Davidson, D. (1967). The logical form of action sentences. In Rescher, N. (Ed.) The logic of decision and action (pp. 81-95). Pittsburgh: Pittsburgh University Press.

15. Dowty, D., Wall, R.E., Peters, S. (1981). Introduction to Montague semantics. Dordrecht: Kluwer Academic Publishers.

16. Enderton, H.B. (2002). A mathematical introduction to logic. San Diego: Academic Press.

17. Florio, S. (2014). Untyped pluralism. Mind, 123(490), 317-337.

18. Florio, S., \& Linnebo, Ø. (Forthcoming). The many and the one: A philosophical study of plural logic. Oxford: Oxford University Press.

19. French, R. (2016). An argument for the ontological innocence of mereology. Erkenntnis, 81, 683-704.

20. Gillon, B.S. (1992). Towards a common semantics for English count and mass nouns. Linguistics and Philosophy, 15, 597-639.

21. Gillon, B.S. (2012). Mass terms. Philosophy Compass, 7(10), 712-730.

22. Goodman, N., \& Quine, W.V. (1955). Steps toward a constructive nominalism. Journal of Symbolic Logic, 12(4), 105-122.

23. Halbach, V. (2010). Axiomatic theories of truth. Cambridge: Cambridge University Press.

24. Higginbotham, J. (1998). On higher-order logic and natural language. In Smiley, T. (Ed.) Philosophical logic (pp. 1-27). Oxford: Oxford University Press.

25. Higginbotham, J. (2000). On events in linguistic semantics. In Pianesi, F., \& Varzi, A. (Eds.) Speaking of events (pp. 49-79). Oxford: Oxford University Press.

26. Hovda, P. (2009). What is classical mereology? Journal of Philosophical Logic, 38, 55-82.

27. Ionin, T., \& Matushansky, O. (2018). Cardinals. The syntax and semantics of cardinal-containing expressions. Cambridge: MIT Press.

28. Krämer, S. (2014). Semantic values in higher-order semantics. Philosophical Studies, 168, 709-724.

29. Krifka, M. (1989). Nominal reference, temporal constitution and quantification in event semantics. In R. Bartsch, R., van Benthem, J., van Emde Boas, P. (Eds.) Semantics and contextual expression (pp. 75-115). Dordrecht: Foris Publications.

30. Krifka, M. (1998). The origins of telicity. In Rothstein, S. (Ed.) Events and grammar (pp. 191-235). Dordrecht: Kluwer Academic Publishers.

31. Landman, F. (1989). Groups, I. Linguistics and Philosophy, 12, 559-605.

32. Landman, F. (1991). Structures for semantics. Dordrecht: Kluwer Academic Publishers.

33. Landman, F. (2000). Events and plurality. Dordrecht: Kluwer Academic Publishers.

34. Landman, F. (2020). Iceberg semantics for mass nouns and count nouns. A new framework for Boolean semantics. New York: Springer International Publishing.

35. Larson, R., \& Segal, G. (1995). Knowledge of meaning: An introduction to semantic theory. Cambridge: MIT Press.

36. Lasersohn, P. (1995). Plurality, conjunction and events. Dordrecht: Kluwer Academic Publishers.

37. Laycock, H. (2006). Words without objects. Oxford: Clarendon Press.

38. Leonard, H.S., \& Goodman, N. (1940). The calculus of individuals and its uses. Journal of Symbolic Logic, 5(2), 45-55.

39. Lewis, D. (1991). Parts of classes. Oxford: Basil Blackwell.

40. Link, G. (1983). The logical analysis of plurals and mass terms: A lattice-theoretical approach. In Bäuerle, R., Schwarze, C., von Stechov, A. (Eds.) Meaning, use and the interpretation of language (pp. 303-323). Belin: De Gruyter.

41. Link, G. (1998). Algebraic semantics in language and philosophy. Stanford: CSLI Publications.

42. Linnebo, Ø. (2003). Plural quantification exposed. Noûs, 37(1), 71-92.

43. Linnebo, Ø. (2006). Sets, properties, and unrestricted quantification. In Rayo, A., \& Uzquiano, G. (Eds.) Absolute generality (pp. 149-178). Oxford: Oxford University Press.

44. Linnebo, Ø. (2017). Plural quantification. In Zalta, E.N. (Ed.) The Stanford Encyclopedia of Philosophy (Summer 2017 ed.). Metaphysics Research Lab, Stanford University. https://plato.stanford.edu/ archives/sum2017/entries/plural-quant/.

45. Linnebo, Ø., \& Rayo, A. (2012). Hierarchies ontological and ideological. Mind, 121(482), $269-308$.

46. Massey, G.J. (1976). Tom, Dick, and Harry, and all the King's men. American Philosophical Quarterly, 13(2), 89-107. 
47. McKay, T.J. (2006). Plural predication. Oxford: Oxford University Press.

48. McKay, T.J. (2015). Stuff and coincidence. Philosophical Studies, 172, 3081-3100.

49. Meadows, T. (2016). Sets and supersets. Synthese, 193, 1875-1907.

50. Moltmann, F. (1997). Parts and wholes in semantics. Oxford: Oxford University Press.

51. Moltmann, F. (2017). A plural reference interpretation of three-dimensional syntactic trees. In Halpert, C., Kotek, H., van Urk, C. (Eds.) A pesky set: Papers for David Pesetsky (pp. 103-109). Cambridge: MIT Press.

52. Montague, R. (1974). The proper treatment of quantification in ordinary English. In Thomason, R.H. (Ed.) Formal philosophy. Selected papers of Richard Montague (pp. 247-270). London: Yale University Press.

53. Nicolas, D. (2002). La distinction entre noms massifs et noms comptables. Aspects linguistiques et conceptuels. Leuven: Editions Peeters.

54. Nicolas, D. (2007). Can mereological sums serve as the semantic values of plurals? Working paper. Open archive HAL. https://jeannicod.ccsd.cnrs.fr/ijn_00176868.

55. Nicolas, D. (2008). Mass nouns and plural logic. Linguistics and Philosophy, 31, 211-244.

56. Nicolas, D. (2018). The logic of mass expressions. In Zalta, E.N. (Ed.) The Stanford Encyclopedia of Philosophy (Winter 2018 ed.). Metaphysics Research Lab, Stanford University. https://plato.stanford. edu/archives/win2018/entries/logic-massexpress/.

57. Oliver, A., \& Smiley, T. (2001). Strategies for a logic of plurals. Philosophical Quarterly, 51(204), 289-306.

58. Oliver, A., \& Smiley, T. (2016). Plural logic, Second edition, revised and enlarged. Oxford: Oxford University Press.

59. Parsons, T. (1990). Events in the semantics of English: A study in subatomic semantics. Cambridge: MIT Press.

60. Pearson, H. (2011). A new semantics for group nouns. In Byram Washburn, M., McKinney-Bock, K., Varis, E., Sawyer, A., Tomaszewicz, B. (Eds.) Proceedings of the 28th West Coast Conference on Formal Linguistics (pp. 160-168). Somerville: Cascadilla Proceedings Project.

61. Pelletier, J.F., \& Schubert, L. (2003). Mass expressions. In Gabbay, D.M., \& Guenthner, F. (Eds.) Handbook of philosophical logic, (Vol. 10, pp. 249-335). Dordrecht: Kluwer Academic Publishers.

62. Pontow, C., \& Schubert, R. (2006). A mathematical analysis of theories of parthood. Data \& Knowledge Engineering, 59(1), 107-138.

63. Quine, W.V. (1986). Philosophy of logic, 2nd edn. Cambridge: Harvard University Press.

64. Quine, W.V.O. (1960). Word and object. Cambridge: MIT Press.

65. Rayo, A. (2002). Word and objects. Noûs, 36(3), 436-464.

66. Rayo, A. (2006). Beyond plurals. In Rayo, A., \& Uzquiano, G. (Eds.) Absolute Generality (pp. 220254). Oxford: Oxford University Press.

67. Rayo, A., \& Uzquiano, G. (1999). Toward a theory of second-order consequence. Notre Dame Journal of Formal Logic, 40(3), 315-325.

68. Resnik, M. (1988). Second-order logic still wild. Journal of Philosophy, 85(2), 75-87.

69. Rieppel, M. (2015). Pluralities and plural logic. Analysis, 55(3), 504-514.

70. Rothstein, S. (2017). Semantics for counting and measuring. Cambridge: Cambridge University Press.

71. Schein, B. (1993). Plurals and events. Cambridge: MIT Press.

72. Schwarzschild, R. (1996). Pluralities. Dordrecht: Kluwer Academic Publishers.

73. Schwarzschild, R. (2006). The role of dimensions in the syntax of noun phrases. Syntax, 9(1), 67-110.

74. Sharvy, R. (1980). A more general theory of definite descriptions. Philosophical Review, 89(4), 607624.

75. Simons, P. (1987). Parts: A study in ontology. Oxford: Clarendon Press.

76. Sutton, P.R., \& Filip, A. (2016). Mass/count variation: a mereological, two-dimensional semantics. The Baltic International Yearbook of Cognition, 11, 1-45.

77. Tarski, A. (1935a). Der Wahrheitsbegriff in den formalisierten Sprachen. Studia Philosophica, 1, 261-405. (Translated as "The concept of truth in formalized languages" in A. Tarski, 1983, Logic, semantics, metamathematics. Papers from 1923 to 1938, translated by J. H. Woodger, second ed., edited and introduced by J. Corcoran, pp. 152-278, Indianapolis: Hackett Publishing Company).

78. Tarski, A. (1935b). Zur Grundlegung der Boole'schen Algebra I. Fundamenta Mathematicae, 24, 177-98. (Translated as "On the foundations of Boolean algebra" in A. Tarski, 1956, Logic, semantics, metamathematics. Papers from 1923 to 1938, translated by J. H. Woodger, second ed., edited and introduced by J. Corcoran, pp. 320-341, Indianapolis: Hackett Publishing Company). 
79. Varzi, A. (2014). Counting and countenancing. In Cotnoir, A.J., \& Baxter, D.L.M. (Eds.) Composition as identity (pp. 47-69). Oxford: Oxford University Press.

80. Varzi, A. (2019). Mereology. In Zalta, E.N. (Ed.) The Stanford Encyclopedia of Philosophy (Spring 2019 ed.). Metaphysics Research Lab, Stanford University. https://plato.stanford.edu/archives/ spr2019/entries/mereology/.

81. Wellwood, A. (2019). The meaning of more. Oxford: Oxford University Press.

82. Williamson, T. (1998). Indefinite extensibility. Grazer Philosophische Studien, 55(1), 1-24.

83. Williamson, T. (2003). Everything. Philosophical Perspectives, 17(1), 415-465.

84. Yi, B.-U. (1999). Is two a property? Journal of Philosophy, 96(4), 163-190.

85. Yi, B.-U. (2005). The logic and meaning of plurals. Part I. Journal of Philosophical Logic, 34, 459506.

86. Yi, B.-U. (2006). The logic and meaning of plurals. Part II. Journal of Philosophical Logic, 35, 239288.

87. Yi, B.-U. (2016). Quantifiers, determiners, and plural constructions. In Carrara, M., Arapinis, A., Moltmann, F. (Eds.) Unity and plurality: Logic, philosophy, and linguistics (pp. 121-170). Oxford: Oxford University Press.

Publisher's Note Springer Nature remains neutral with regard to jurisdictional claims in published maps and institutional affiliations. 